\title{
THE STAMMERING PROBLEM SOLVED
}

BY ERNEST TOMPKINS, M. E.

7 HAT THE article by the Blantons entitled "What is the Problem of Stuttering" in the February, I919, Journal of Abnormal Psychology leaves something to be desired, may be seen from the summary, which reads, " . . . there is or may be postulated some hereditary or acquired weakness in the field: of emotional adaptation plus some hereditary or acquired weakness: of the adaptive functions of speech, presumably in the kinesthetic, auditory or visual centers." Instead of definiteness we have in this sentence, "may be," two "somes," "presumably," and then indecision as between the "kinesthetic, auditory or visual centers." Since the authors themselves, in the same article, make a strong and worthy plea for settlement of the stammering problem, they will surely welcome a settlement.

Some one will say, "How can there be a settlement when the field is so confused?" And the question would seem rèasonable in face of the glaring contradictions which are constantly appearing in the articles on the subject. The answer will be that if there can be a settlement it must be by scientific procedure, and that necessitates the establishment of a tenable theory. After we have the theory established the rest is easy. Let us take an illustration from the field of astronomy in order to convince those who, from unsatisfactory experience with fallacious theories, are accustomed to doubt all theories. When Kepler summed up all the reliable observations of the paths of planets: and satellites in the conception that their paths are ellipses, he formulated a theory so comprehensive that it is accepted as the truth: we no longer call it a theory. And when some observer announcessomething different, we are not disturbed in our belief, for we know that Kepler's conception crystallizes the myriads of reliable observations. The new observer may be perfectly honest, but there is something wrong with his observation.

Now is there a theory in the field of stammering as reliable as Kepler's theory in the field of astronomy. Yes, there is; but it is not generally recognized because it is opposed by the same prejudice which opposed the views of Kepler, Galilei and all the other intellectual pioneers. This theory has been detailed so many times during the last 
five years that it would be burdensome to give even the numerous references. The article in the Pedagogical Seminary for June, 1916, gives a comprehensive idea of it. Since the many expositions of it in the medical and scientific press stand undisputed, and since it accounts for all the manifold and perplexing manifestations of the disorder, it must be accepted as a working theory, provided we are to be scientific, and that is the understanding. Let us satisfy any who would question our right to proceed. Suppose he says, "I hold to the thymus theory, or to the auditory-amnesia theory, or to the visual-asthenia theory." But none of those theories accounts for the acquisition of stammering by imitation or association, and the speech-interference theory does account for such acquisition and for all other manifestations of the disorder, so we must accept the speech-interference theory. And the same statement holds true for any other theory that has ever been propounded. So there is no choice but to proceed on the basis of the speech-interference theory.

What is the speech interference theory? It is that the stammerer impedes his speech by a misdirected, conscious effort impelled by his fright. "Let the reader grasp this fact-for fact it is, and anyone can see it--that the stammerer makes his own difficulty. Of course he has the fright, or emotion, but that is the result of the humiliation caused by his impediment. How did it begin? Why, by a temporary' speech-interruption, the long sought common causal factor that has upset every other theory in the field. Dr. Makuen died without knowing that common causal factor. In the origin by imitation the interruption is intentional, by association it is unintentionally imitative, by fright it is the paralysis of terror, by sickness it is weakness. Once the temporary interruption induces the misdirected conscious effort, then the unkindness of society makes the humiliation which builds up the incomprehensibly tenacious fear.

Now we have our theory, let us use it. Is stammering coincident with the beginning of speech? No. How can one interfere with his speech if he has none with which to interfere? He can not. Speech must be acquired-speech always is acquired-before stammering can begin, notwithstanding that determined contestant who altered some of his previously published histories in order to prove the contrary! (Quarterly Journal of Speech Education, October, I9 I 8, p. 454).

Can stammering be inherited? No. If it was inherited, it would be dissipated during the fluent period of speech acquisition. For, just as impeded speech builds up the fear which continues the disorder, 
so fluent speech builds up the confidence which dissipates the disorderOf course there are the numerous "proofs" of inheritance, such as. Rudolf Denhardt's, traced back so many generations that approximately $100 \%$ inheritance of stammering, or measles, could be proved; such as Makuen's, which on the face of it, by summation of the percentages of causes he gives, turns out a mathematical disproof; such as the innumerable surmises of inheritance from a few occurrences of the disorder in different generations of the same family; but what a pity it is, what a travesty it is, to present such reasoning as medical science. Excepting the political vagaries which are unsetting the world there can probably be no greater wrong to the race than to keep the healing art down to the level of mere speculation and even worse. There is no more persistent error in connection with stammering than this interminably repeated inheritance, which not only lacks foundation in observation-just as much as inheritance of measles does-but which is actually barred from existence by the very nature of the disorder.

Has the stammerer any typical characteristics other than his stammering? No. Provided he had speech to begin with, and provided the temporary interruption occurred, he would stammer, and by stammering he would increase his difficulty until he had small chance of recovery. He might be immoral, he might be neurotic, he might be a coward, he might have an enlarged thymus, he probably would have sex; but his having any or all of those things would not make him a stammerer, nor would his being a stammerer bring on him any of those things. Let those who would dispute, do so. Say, if you please that his stammering would make him a neurotic. Let us consider that statement on its merits. Society humiliates him because it finds his antics funny. The humiliation pains him, and he dreads the repetition of it. But is a dog a neurotic because bad boys tie tin cans to its tail whenever they catch it? If the boys desist from plaguing the dog it will behave normally; and if society would desist from humiliating the stammerer he would not only behave normally, but would begin to recover. Most of the girls do recover on account of the greater consideration shown them. Go to any of the stammering schools and see the light-heartedness of those pupils whose quickly acquired fluency has convinced them that they are free from their affliction. Do they act neurotic? Not by any means. They almost walk on air. The long and short of it is that the charges against the stammerer of innumerable deficiencies are as baseless as they are cruel. He has a complicated, self-intensifying habit of extreme tenacity after 
it has run for a time. And he is kept in the habit by the cruelty of society and by commercialism and faulty observation, both of which latter combine to hide the habit nature of the disorder and to represent it as a disease.

What is the solution? Extirpate the disorder by forbidding childhood indulgence in the convulsive efforts. Is that anything new? $\mathrm{No}$; it is comparatively common knowledge. Otherwise there would be twice as much stammering as there is. This monumental confusion of the subject - a feature harped on as loudly as on the need of really doing something to abate it-exists only in our learned discussions of the subject. Turn to Chamber's encyclopedia of fifty years ago and you may therein read a better discussion of stammering than can be found in any modern reference book or encyclopedia. The hands of the clock have been turned back, and the modern literature on the subject is more erroneous than it was two generations ago. You find in that discussion that stammering is classified as a habit and the word habit is underscored. Do you find that to-day? Pas sur vôtre vie. One more-or-less prominent authority who was disseminating a discussion of stammering which he himself pronounced the finest discussion in the English language, on having called to his attention the fact that he had frequently and inadvertently mentioned the disorder as a habit, withdrew this superior discussion and substituted for it another which held much more rigidly to the disease classification. But the biogenetic law, and Mendelism, and evolution met with the same reception; so we may conclude that not yet, nor even soon, but possibly within a couple of generations the stammerers will get the justice which has been denied them since the race became human. 